\title{
PENGARUH KARAKTERISTIK TIM, DAN KEPERCAYAAN TERHADAP KINERJA PEGAWAI TATA USAHA SMA NEGERI DI KABUPATEN BONE PROVINSI SULAWESI SELATAN
}

\author{
Syamsuddin*
}

\begin{abstract}
The aim of this research is to examine the effect of team characteristic and trust on job performance. The Research has been implemented by using path analysis, after all variables put into a matrix of correlation. In this research, employees had been choosen as a unit analysis and 104 samples selected by randomly. The result of research indicates: (1) there is direct effect of team characteristic on job performance, (2) there is direct effect of trust on job performance, (3) there is direct effect of team characteristic on trust. Based on those finding it could be concluded that any changing or variation wich occured to the job performance of administration employees of State Senior High School at Bone Regency in South Sulawesi Province had been effected by team characteristic and trust
\end{abstract}

Keyword: Team characteristic, trust, and job performance

\section{PENDAHULUAN}

Pegawai tata usaha merupakan salah satu komponen pendidikan yang memiliki peran yang cukup signifikan dalam penyelenggaraan pendidikan pada setiap tingkat pendidikan adalah tenaga kependidikan atau pada tingkat sekolah dasar hingga sekolah menengah atas lebih dikenal dengan istilah pegawai tata usaha. Sebagai salah satu komponen pendidikan yang memiliki peran penting khususnya terkait masalah pelayanan adminsitrasi sekolah maka seharusnya para pengambil kebijakan pendidikan memberikan perhatian yang baik terhadap pegawai tata usaha sekolah.

Pegawai tata usaha di lembaga pendidikan tingkat sekolah memiliki peran dan fungsi yang strategis. Peran dan fungsi tersebut berupa penyelenggaraan tugas administrasi sekolah, informasi, dan memberikan layanan terhadap siswa, guru, dan pimpinan sekolah serta seluruh pihak yang berkepentingan. Oleh karena itu, peran dan fungsi pegawai tata usaha di sekolah tidak dapat diabaikan bahkan dapat dianggap sebagai salah satu penunjang penyelenggaraan pendidikan di tingkat sekolah yang berkualitas.

Berbagai peran dan fungsi pegawai pada sistem pengelolaan sekolah tersebut semakin penting semenjak diberlakukannya Undang-undang Otonomi Daerah pada tahun 1999 telah melahirkan sistem pendidikan yang desentralitatif yang dalam dunia pendidikan dikenal dengan istilah program manajemen berbasis sekolah. Program tersebut tentu menuntut tersedianya pegawai sekolah yang mampu berkontirbusi positif sebagai upaya peningkatan mutu sekolah sesuai kebutuhan masyarakat sekitar. Selain keahlian dan keterampilan yang memadai, tentu juga sangat diharapkan pegawai yang memiliki visi sebagai sebuah tim kerja sekolah serta komitmen yang kuat untuk senantiasa berusaha meningkatkan kinerja.

\footnotetext{
* Tenaga Wiyata Bhakti STAIN Watampone
} 
Akan tetapi, mutu dan kinerja pegawai tata usaha yang selama ini diharapkan menurut Junaidi ((2013:1) pada kenyataannya masih cenderung masih rendah. Hal ini bisa disebabkan karena peranan pegawai tata usaha luput dari pantauan banyak orang sehingga pegawai tata usaha masih belum memberikan kotribusi yang optimal terhadap peningkatan mutu pendidikan.Sangat jarang kita temui seorang pegawai tata usaha mendapatkan pendidikan dan pelatihan serta seminar.

Hal tersebut dipertegas oleh Sekretaris Dinas Pendidikan Kabupaten Bone Provinsi Sulawesi Selatan bahwa kinerja pegawai TU memang masih cenderung belum optimal jika dilihat dari berbagai indikator seperti masih banyaknya pegawai tata usaha yang belum memliki kemampuan atau keahlian yang memadai untuk melaksanakan tugasnya yang terlihat dari kemampuan mengoperasikan komputer yang relatif rendah dan pengarsipan data-data sekolah yang kurang lengkap serta tidak aktual.

Fakta di atas dengan jelas memberikan kita gambaran bahwa tidak dapat dinaifkan pegawai tata usaha sebagai tenaga kependidikan di tingkat sekolah belum opimal atau belum sesuai dengan harapan. Hal ini tentu harus mendapat perhatian serius dari segenap pihak mengingat peran dan fungsi pegawai tata usaha sebagai salah satu penyelenggara pendidikan diperlukan kinerja yang optimal guna menunjang penyelenggaraan pendidikan yang berkualitas.

\section{Kinerja}

Pada dasarnya kinerja adalah tingkat pencapaian pelaksanaan tugas pegawai berdasarkan wewenang dan tanggung jawabnya.Untuk mencapai kinerja yang baik tentu bukanlah suatu hal yang mudah.Hal ini disebabkan banyaknya hal atau aspek yang berpengaruh terhadap tingkat kinerja seorang pegawai baik itu aspek mekanisme organisasi, mekanisme grup, karakteristik individu, maupun mekanisme Individual.

Menurut Wibowo (2012:7) kata kinerja berasal dari kata "performance"sehingga performance diartikan sebagai hasil kerja atau prestasi kerja. John W. Newstrom dan Keith Davis (2002:29) menyatakan bahwa "performance: the outcomes, or end results, are typically measured in various forms of three criteria: quantity and quality of products and services; level of customer service". Kinerja merupakan hasil atau hasil akhir yang biasanya diukur berdasarkan pada tiga kriteria, yaitu kuantitas dan kualitas produk serta layanan berupa tingkat pelayanan pelanggan.

Menurut Lioyd (2011:214) "job performance is the net effect of an employee's effort as modified by abilities and role (or task) perception". Kinerja adalah efek bersih dari upaya pegawai yang dimodifikasi berdasarkan persepsi kemampuan dan peran (tugas).

Gibson, Ivancevich, Donelly, dan Konopaske (2012:374) mengemukakan bahwa "job performance is the outcomes of jobs that relate to the purposes of the organizations such as qulity, efficiency, and other criteria of effectiveness".Kinerja adalahhasildaripekerjaanyang berhubungan dengan tujuan organisasi seperti kualitas pelayanan, efisiensi, dan kriteria efektivitas lainnya.

Menurut Colquitt (2011:35) "job performance is formally defined as the value of the set of employee behaviors that contribute, either positively or negatif, to organizational goalaccomplishment". Kinerja secara formal didefinisikan sebagai nilai-nilai yang terangkum pada tingkah laku pegawai baik yang positif maupun negatif untuk mencapai tujuan organisasi. Colquitt juga menambahkan tiga dimensi kinerja yaitu: (1) kinerja tugas (taskperformance), perilaku kesukarelaan (citizenshipbehavior) sebagai kontribusi perilaku positif, dan (3) perilaku produktif tandingan (counterproductive) sebagai kontribusi perilaku negatif. 
Lebih lanjut Steve M. Jex (2002:88) juga mengatakan bahwa "job performance is a deceptively simple term at the most general level, it can be defined simply as all of the behaviors employees engage in while at work". Kinerja merupakan sebuah istilahyang sederhana pada tingkat yang paling umum dan dapat didefinisikan sebagai perilaku positif karyawan dalam bekerja.

Stephen Robbins dan Mary Coulter (2012:492) mengutarakan bahwa kinerja sebagai "the end of results of an activity", yakni hasil dari aktivitas. Hal ini menunjukkan bahwa hasil kerja yang efektif dan efisien yang dicapai oleh seorang pegawai dalam melaksanakan tugasnya sesuai dengan tanggung jawab yang diberikan kepadanya.

Sementara Luthans (2008:374) menekankan pada kuantitas atau kualitas sesuatu yang dihasilkan atau jasa yang diberikan oleh seseorang yang melakukan pekerjaan. Hal ini diutarakan dalam pendapatnya bahwa"behavior performance management is not a good idea to be tried for a while and then cast aside for some other good idea. It is a science that explains how people behave. It can not go away anymore tha gravity can go away. In a changing world, the science of behavior must remain the bedrock, the starting place for every new technology we apply, and every initiative we employee in our effort to bring out the best in people".

Di sisi lain, Amstrong (2006:7) berpendapat bahwa "performance is often defined simply in output terms-the achievement of quantiffied objectives." Kinerja didefinisikan secara sederhana dalam konteks hasil merupakan prestasi dari pengukuran sasaran hasil. Pengertian ini menghubungkan antara hasil kerja dengan perilaku. Kinerja merupakan aktivitas pegawai yang diarahkan pada pelaksanaan tugas organisasi yang disebabkan kepadanya. Pengarahan tingkah laku tersebut dilakukan melalui acuan kerja berupa sasaran hasil kerja. Hal ini dapat berbentuk peraturan, deskripsi tugas pokok dan fungsi kerja, dan arahan serta otoritas organisasi. Dengan demikian pencapaian sasaran melalui berbagai arahan menjadi harapan tingkat pencapaian pegawai.

Berdasarkan beberapa konsep di atas dapat disintesiskan kinerja adalah perilaku kerja seseorang berdasarkan pada target dan kriteria yang telah ditetapkan dengan indikator (1) melaksanakan pekerjaan, (2) penyelesaian tugas, (3) mengembangkan keahlian dalam bekerja, dan (4) berprestasi dalam bekerja.

\section{Kepercayaan}

Kepercayaan merupakan salah satu aspek yang mendapatkan perhatian dan banyak dibahas oleh para ahli manajemen, baik yang terdapat di dalam referensi dasar manajemen maupun perilaku organisasi. Colquit et.al (2011:219) mendefinisikan kepercayaan sebagai "trust is defined as the willingness to be a vulnerable to an authority's actions and intentions". Kepercayaan didefinisikan sebagai kesediaan untuk menjadi rentan menerima otoritas berdasarkan harapan positif dari niat dan tindakan yang dipercayai.

Sementara Robbins dan Timothy Judge (2011:429) menyatakan bahwa "trust is a positive expectation that another will not-trouhgh words, action, or decision-act opportinistically". Kepercayaan adalah harapan positif bahwa orang lain tidak akan berbuat oportunistik baik melalui perkataan, tindakan, maupun keputusan. Istilah opportunistik mengacu pada resiko dan kerawanan bawaan di dalam hubungan berbasis kepercayaan. Kepercayaan menjadi rawan di saat, misalnya membuka informasi pribadi atau berpegang teguh pada janji orang lain. Hal tersebut berarti bahwa jika kepercayaan luntur akan berdampak serius terhadap kinerja tim. Begitu pula sebaliknya jika sesama pegawai saling mempercayai maka mereka akan bersedia menanggung dampak dari tindakan yang diambil secara bersama-sama. 
John W. Newstrom dan Keith Davis (2002:263) mengemukakan bahwa "trust is the capacity to depend on each other's word and action". Kepercayaan adalah kapasitas untuk bergantung pada setiap kata dan tindakan.

Sementara itu, Mcshane dan Von Glinow (2010:52) juga berpendapat tentang kepercayaan sebagai sebuah harapan yang terjadi dalam dua arah bahwa "trust refers to positif expectation one person has toward another person in situations involving risk. A high level of trus occurs when others affect you in situations where you are at risk but you believe they will not harm you. Trust includes both your beliefs and conscious feeling about the relationship with other members". Suatu kepercayaan memberi harapan positif seseorang terhadap orang lain pada situasi yang beresiko. Sebuah tingkat kepercayaan yang tinggi terjadi ketika orang lain mempengaruhi Anda dalam situasi yang beresiko tetapi Anda percaya bahwa mereka tidak akan membahayakan Anda. Kepercayaan mencakup keyakinan dan perasaan sadar tentang hubungan dengan anggota lain.

Richard L. Daft (2008:265) mengemukakan pengertian kepercayaan bahwa "trust is an essential element in effective leader-follower relationships because it inspires collaboration and commitment to comon goals". Kepercayaan adalah elemen penting dalam efektifivitas hubungan pemimpin dengan bawahan karena mengilhami kolaborasi dan komitmen untuk tujuan bersama.

Stephen P. Robbins dan Mary Coulter (2012:473) menjelaskan bahwa "trust is defined as the belief in the integrity, character, and ability of a leader". Kepercayaan didefinisikan sebagai kepercayaan pada integritas, karakter, dan kemampuan seorang pemimpin.

Berdasarkan berbagai uraian di atas dapat disintesiskan kepercayaan adalah harapan positif seseorang terhadap orang lain terkait dengan pelaksanaan tugas dengan indikator berupa (1) adanya keyakinan terhadap orang lain, (2) adanya anggapan positif, (3) mengakui kemampuan orang lain, (4) adanya hubungan sosial yang baik, dan (5) kesempatan dalam bertindak.

\section{Karakteristik Tim}

Pengertian tim yang mendeskripsikan karakteristik khusus suatu tim secara mendasar dijelaskan oleh Colquitt et.al (2011:375) bahwa karakteristik tim adalah " two or people who work interdependently over some time period to accoplish common goals related to some task-oriented purpose". Dua atau lebih orang yang bekerja saling bergantung dalam waktu tertentu melengkapi tujuan tertentu yang berkaitan dengan maksud dan orientasi tugas.

Sementara John W. Slocum (2009:321) mengatakan bahwa "a team is small member of employees with complementary competencies who are committed to common performances goals and working relationship for wich they hold themselves mutually accountable". Suatu tim adalah sejumlah anggota kecil dari pegawai dengan kemampuan saling melengkapi, komitmen terhadap tujuan kinerja bersama, dan hubungan kerja, yang satu sama lain saling bertanggung jawab.

Selanjutnya menurut Richard L. Daft (2010:476) bahwa"team characteristic of particular concern are size, diversity, and member roles". Perhatian khusus tim karakteristik adalah ukuran, keragaman, dan anggota peran. "One of e leader's most important job is to get the team designed right by consedering such characteristic as size, diversity, and interdependence". Salah satu pekerjaan penting seorang pemimpin yang utama adalah mendesain tim dengan tepat dengan mempertimbangkan karakteristik atau ciri khususnya seperti ukuran, keragamaan, dan saling ketergantungan. 
Selanjutnya Gary Yulk (2010:356) menjelaskan bahwa "common characteristic of teams, autonomy to determine mission and objectives, autonomy to determine work procedures, authority on the internal leader, duration of existence for the team, stability of the membership, and diversity of membership, and diversity of members in functional background". Pada umumnya karakteristik tim itu berupa kemandirian dalam menentukan misi dan tujuan, kemandirian untuk menentukan prosedur kerja, kekuasaan pimpinan internal, masa keberadaan tim, stabilitas keanggotaan, dan perbedaan latar belakang fungsional anggota.Pada umumnya karakteristik tim itu berupa kemandirian dalam menentukan misi dan tujuan, kemandirian untuk menentukan prosedur kerja, kekuasaan pimpinan internal, masa keberadaan tim, stabilitas keanggotaan, dan perbedaan latar belakang fungsional anggota.

Baldwin (2008:259) mengatakan bahwa"a team is not just people who work for the same manager or whose workspaces are located near one another. Rather, a team is a group that shares responsibility for producing something together. People often confuse interdependence with personal contact. Simply working closely with others, however, does not make a team. Teams are unique because member can not complete the work without the work of other members. As we noted earlier, just because a team is brought together hardly ensures it will be high performing. Below we highlight what defines a high performances and the key characteristic, or disciplines that contribute to such performance". Sebuah tim bukan sekedar sekelompok orang yang bekerja pada manajer yang sama atau bekerja pada lokasi yang berdekatan. Akan tetapi, sebuah merupakan grup yang saling berbagi tanggung jawab untuk memproduksi sesuatu secara bersama-sama. Orang sering membingungkan keterkaitan tugas dengan kontak pribadi. Bekerja sama dengan orang lain namun itu tidak membentuk suatu tim. Tim merupakan suatu hal yang unik karena anggota tidak dapat menyelesaikan pekerjaannya tanpa bekerja. Berdasarkan hal yang telah dijelaskan sebelumnya bahwa hanya dengan tim yang saling bekerja sama, maka hampir dipastikan akan berkinerja tinggi. Uraian tersebut menyoroti hal yang mendefinisikan kinerja yang tinggi dan kunci karakteristik sebuah tim atau disiplin yang berkontribusi terhadap kinerja.

Berdasarkan berbagai kajian konsep dapat disintesiskan karakteristik tim adalah komposisi tim kerja dan keterkaitan anggota tim dalam melaksanakan tugas yang telah ditetapkan, yang ditunjukkan dengan indikator berupa (1) perbedaan atribut anggota, (2) peranan anggota, (3) keterkaitan tugas, dan (4) keterkaitan tujuan.

\section{METODE}

Metode peneltian yang digunakan pada penelitian ini adalah metode survey, dengan pendekatan korelasional. Penelitian ini dilakukan di SMA Negeri Kabupaten Bone Provinsi Sulawesi Selatan. Populasi dalam dalam penelitian ini adalah seluruh pegawai tata usaha yang bertugas di bawah naungan Kantor Dinas Pendidikan Kota Bone. Populasi terjangkau pada penelitian ini sebanyak 140 orang dengan sampel sebanyak 140 orang. Pengambilan sampel menggunakan teknik Simple Random Sampling.

Penelitian ini menggunakan analisis jalur (Path Analysis) untuk mengetahui adanya pengaruh antar variabel sesuai dengan model kausal yang terbentuk.Sebelum kuesioner digunakan dalam penelitian ini, terlebih dahulu dilakukan ujicoba untuk menentukan validitas dan reliabilitas instrumen.Hasil tersebut digunakan sebagai instrumen untuk mengambil data penelitian di lapangan. Analisis data meliputi: 1) deskripsi data, 2) uji prasyarat analisis normalitas, 3) analisis jalur yang meliputi: analisis model, pengujian hipotesis dan penentuan tingkat pengaruh. 


\section{HASIL DAN PEMBAHASAN}

\section{Pengaruh Karakteristik Tim (X1) terhadapKinerja(X3)}

Dari hasil perhitungan analisis jalur, pengaruh langsung Karakateristik Tim terhadap kinerja pegawai tata usaha SMA Negeri Kabupaten Bone. Dari hasil perhitungan diperoleh nilai koefisien jalur sebesar 0,45. Dengan demikian, membentuk karakteristik tim maka pegawai tata usaha dapat meningkatkan kinerja di sekolah. Hal ini sejalan berdasarkan teori Colquitt lebih memperjelas lagi dengan mengatakan bahwa. "task interdependence has a moderate positive effect on team performance". Anggota tim yang memiliki karakateristik tim berupa adanya saling ketergantungan tugas mempenguhi kinerja.

Hal tersebut juga senada dengan pendapat Gary Yukl (2010:411) di atas juga senada dengan pernyataan Gari Yuk bahwa "most of the early research examined how the composition of the team and the mix of member attributes affect the type of decisions made and the performance of organization". Sebagian besar penelitian terbaru menguji bagaimana komposisi tim dan atribut anggota tim yang bercampur-baur mempengaruhi tipe keputusan dan kinerja organisasi.

\section{Pengaruh Kepercayaan (X2) terhadapKinerja (X3)}

Dari hasil perhitungan analisis jalur, pengaruh langsung Karakateristik Tim terhadap kinerja pegawai tata usaha SMA Negeri Kabupaten Bone. Dari hasil perhitungan diperoleh nilai koefisien jalur sebesar 0,268. Dengan demikian, meningkatkan kepercayaan pegawai tata usaha dapat meningkatkan kinerja di sekolah.

Hal ini sesuai dengan yang diungkapkan oleh Colquitt bahwa "employees who are willing to be vulnerable to authorities tend to higher level of task performance". Pegawai yang memilki kepercayaan terhadap pimpinan cenderung memiliki tingkat kinerja yang lebih tinggi. Bahkan secara tegas diungkapkan oleh Colquitt juga bahwa "trust has a moderate positive effect on performance". Kepercayaan memiliki efek positif terhadap kinerja. Hal ini berarti semakin tinggi tingkat kepercayaan seorang pegawai maka cenderung juga memiliki kinerja yang lebih baik.

\section{Pengaruh Karakteristik Tim (X1) terhadap Kepercayaan (X2)}

Dari hasil perhitungan analisis jalur, pengaruh langsung Karakateristik Tim terhadap kinerja pegawai tata usaha SMA Negeri Kabupaten Bone. Dari hasil perhitungan diperoleh nilai koefisien jalur sebesar 0,425. Dengan demikian, membentuk karakteristik tim maka pegawai tata usaha yang baik dapat meningkatkan kepercayaan baik antar pegawai maupun terhadap kepala sekolah.

Hal ini senada dengang pendapat Mc. Shane (2008:365) bahwa "declining trust is particularly challenging in virtual temas because research identifies communication among team members as an important conditon for sustaining trust". Kepercayaan merupakan tantangan utama dalam tim karena berdasarkan hasil penelitian, komunikasi antara anggota tim adalah sebagai kondisi utama untuk mempertahankan kepercayaan.

John M. Ivancevich mengemukakan bahwa "trust between team members should be cultivated early in the procces. Face to face meeting and or team-building training exercise should be used during the intial periods of team formation to facilitate the development trust". Kepercayaan antar anggota tim harus segera diperkuat dalam proses tim. Rapat-rapat dan pelatihan dalam membangun tim sebaiknya dimanfaatkan sejak awal pembentukan tim sebagai media untuk mengembangkan tim). Hal tersebut berarti berbagai karakter kegiatan tim baik yang sifatnya kerjasama, interaksi, saling membantu secara 
berkesinambungan dapat berpengaruh terhadap kepercayaan antar anggota tim atau dengan kata lain, baik atau tidaknya karakteristik tim berpengaruh terhadap tingkat kepercayaan anggota tim.

\section{PENUTUP}

\section{Kesimpulan}

Berdasarkan hasil analisis data dan perhitungan statistik sebagaimana yang telah diuraikan pada bab sebelumnya maka temuan dari hasil penelitian ini dapat disimpulkan bahwa:

1. Terdapat pengaruh langsung positif karakteristik tim terhadap kinerja. Artinya peningkatan kinerja harus diawali dengan penguatan karakteristik tim.

2. Terdapat pengaruh langsung kepercayaan terhadap kinerja. Artinya peningkatan kinerja harus diawali dengan meningkatkan kepercayaan baik antar pegawai maupun terhadap pimpinan.

3. Terdapat pengaruh langsung karakteristik tim terhadap kepercayaan. Artinya peningkatan kepercayaan harus diawali terlebih dahulu dengan melakukan penguatan karakteristik tim.

\section{Saran}

Beberapa saran terkait dengan penelitian ini mencakup sebagai berikut:

1. Kepala Dinas Pendidikan Kabupaten Bone selaku pengambil kebijakan tertinggi di satuan pendidikan tingkat kabupaten/kota perlu memperhatikan berbagai variabel berkenaan dengan upaya peningkatan kinerja pegawai tata usaha SMA Negeri di Kabupaten Bone. Karakteristik tim dan kepercayaan merupakan variabel yang sangat disarankan untuk diperhatikan dan diterapkan agar kinerja pegawai tata usaha senantiasa dapat meningkatkan kinerja sesuai dengan harapan.

2. Pihak Kepala Sekolah SMA Negeri di Kabupaten Bone selaku pihak yang langsung melakukan perekrutan pegawai tata usaha agar memperhatikan dengan baik pihakpihak yang akan direkrut atau diterima menjadi pegawai tata usaha di sekolah agar terbentuk komposisi tim pegawai yang baik. Begitu pun dengan pegawai tata usaha yang telah direkrut sebelumnya agar Kepala sekolah senantiasa berupaya meningkatkan keterkaitan tugas antar pegawai. Terbentuknya karakteristik tim pegawai tata usaha yang handal baik dari perspektif komposisi tim maupun keterkaitan tugas antar pegawai yang baik akan menunjang peningkatan kepercayaan baik antar pegawai tata usaha maupun terhadap Kepala Sekolah sehingga pencapaian tingkat kinerja yang diharapkan dapat terwujud. 


\section{DAFTAR RUJUKAN}

Amstrong, Micahel.Performance Managament, Key Strategies and Practical Guidelines. London and Philadephia: Kogan Page, 2006.

Colquitt, Le Pine, and Wesson. Organizational behavior: Improving Performance and Commitment in the work Place. New York: McGrawHill Companies. Inc., 2011.

Daft,Rhicard L.The Leadership Exprience.Canada: South-Western, Part of the Thomson Coorporation, 2005.

Gibson, Donelly, Ivancevich, dan Robert Konopaske.Organizations Behavior, Structure, Processes. New York: McGraw-Hill, 2012.

Junaidi, Menyoal Mutu pegawai TU Sekolah.http://researchengines.com/0807junaidi.html. (diakses 27 Februari 2013).

Lyman,Amy.Trustworthy Leader: Leveraging The Power of Trust to Transform Your Organization.San Fransisco: Jossey-Bass A Wilei Imprint, 2012.

M. Ivancevich, John, Robert Konopaske, dan Michael T. Matteson, Organizational Behavior and Management. Singapore: McGrawhill Education, 2008.

Robbins, Stephen.Timothy A. Judge.Organizational behavior.New Jersey: Perason Education, Inc, 2011.

Steven L.Mc,.Shane and Mary Ann Von Glinow.Organizational Behavior. New York: Mc.Graw-Hill, 2010.

Yulk, Gary.Leadership in Organizations. New Jersey: Pearson Education Inc, 2010.

Wibowo, Manajemen Kinerja. Jakarta: PT Raja Grafindo Persada. 2012. 
